\title{
Blackley and the Development of Hay Fever as a Disease of Civilization in the Nineteenth Century
}

\author{
KATHRYN J WAITE*
}

Recent surveys have estimated that the prevalence of hay fever among modern populations is between 2 and 15 per cent. ${ }^{1}$ Yet there are few references to the condition in any literature before the nineteenth century. Despite this fact, by 1900 hay fever was described as a common and fashionable disease. In this paper I outline the first descriptions of hay fever and how ideas about it developed through the nineteenth century. I then examine in some detail how thoughts about hay fever progressed so that it came to be described as a disease of civilization.

\section{Early References to Hay Fever}

It is claimed that the first known hay fever sufferer may have been Hippias the Athenian traitor who guided the Persian fleet to its landing at Marathon and finally commanded part of the army in the subsequent battle. ${ }^{2}$ Rosen concludes from his researches that there are numerous allusions in the Bible and Talmud which point to the presence of nasal allergy and hay fever. However these claims are somewhat tenuous. A more concrete description is given by Rhazes in a Arabic text entitled 'On the reasons why the heads of people swell at the time of roses and produce catarrh'. 3

References to aversions to roses are documented from the fifteenth and sixteenth centuries and have already been well described by Wood, Mackenzie and Emanuel. ${ }^{4}$ Many of the early authors on the subject of hay fever were themselves sufferers. There are other accounts of rose fever during the seventeenth and eighteenth centuries, and it appears likely from the symptoms given that this ailment was what we term hay fever.

*Kathryn J Waite, BSc, Royal Free Hospital School of Medicine, Pond Street, London NW3.

I would like to thank all the staff at The Wellcome Institute for the History of Medicine for their enthusiastic teaching on the intercalated BSc course. In particular I would like to thank Dr Michael Neve for his continuing support and advice. I would also like to thank Dave Wright for his help with word processing.

${ }^{1}$ For the latest account of the prevalence and incidence of hay fever see: B Sibbald, 'Epidemiology of allergic rhinitis'. Monographs in Allergy, 1993, 31: 61-79, and A M Ross and D M Fleming,

\footnotetext{
'Incidence of allergic rhinitis in general practice, 1981-92', Br. med. J., 1994, 308: 897-900.

$2 \mathrm{~S}$ Wood, 'Review of hay fever. 1. Historical background and mechanisms', Family Practice, 1986, 3: 54-63, p. 55.

${ }^{3} \mathrm{Z}$ Rosen, 'Nasal allergy in Biblical and Talmudic times', Ann. Allergy, 1971, 29: 260-2, p. 262; M B Emanuel, 'Hay fever, a post industrial revolution epidemic: a history of its growth during the 19th century', Clin. Allergy, 1988, 18: 295-304.

${ }^{4}$ For early descriptions of rose fever see Wood, op. cit., note 2 above, p. 55, M Mackenzie, Hay fever and paroxysmal sneezing: their etiology and treatment, 4th ed., London, J and A Churchill, 1887, p. 87.
} 


\section{The Development of Hay Fever as a Disease of Civilization}

\section{Nineteenth-Century Descriptions of Hay Fever}

In 1818 William Heberden (1773-1845), the eminent physician, described a type of chronic catarrh, "I have known it return in four or five persons annually in the months of April, May, June, or July, and last a month with great violence. In one a catarrh constantly visited him every summer; and in another this was the only part of the year in which it ceased to be troublesome". 5 This certainly appears to have been hay fever, however Heberden does not differentiate this condition from catarrh per se, and so the credit for the first description of the disease is given to John Bostock (1773-1846).

In 1819 he published a report of his own case of hay fever from which he had been suffering for more than twenty years. It manifested itself as "a periodical affection of the eyes and chest" which commenced around "the beginning or middle of June in every year". ${ }^{6}$ He went on to say that the condition could "generally, but not always . . . be traced to some exciting cause, of which the most certain is a close moist heat, also a bright glare of light, dust or some other substances touching the eyes, and any circumstance which increases the temperature". ${ }^{7}$ In 1829 he described twenty-eight more cases of what he called "catarrhus aestivus" or literally a summer cold. He noted that the disease occurred only among the "middle or upper classes of society, some indeed of high rank". 8 This idea recurred throughout the nineteenth century and was refuted by only a few.

Bostock had named the disease catarrhus aestivus, but in 1827 the name hay-asthma was first used in a private letter by a non-medical person, indicating a lay knowledge of this disorder. Robert Southey (1774-1835) described a visit that his family had recently made to Harrogate which had an added benefit for him since he "Escaped from the hayasthma with a visit of one month, instead of a visitation of three". 9 Despite the fact that the disease had been described only some ten years earlier and there had been no further references to it in the medical literature, John Macculloch (1773-1835) deemed it appropriate to refer to the disease as a "well-known disorder" which "is produced by hothouses or green-houses; and in the public estimation, it is particularly caused by hayfields. Hence the term Hay fever, lately become fashionable". ${ }^{10}$ This was reiterated by Bostock who wrote that "since the attention of the public has been turned to the subject, an idea has very generally prevailed, that it is produced by the effluvium from new hay, and it has hence obtained the popular name of the hay fever". This is further evidence of an appreciable folk knowledge of this disease. W H Cook (1832-1899) wrote that "from the occurrence of this malady in England about the time of the hay-harvest, it received its popular name of "hay fever". ${ }^{11}$ The term hay fever was therefore first used in the medical literature in 1828, by Macculloch, and had already gained, according to this author, the connotation of fashionability.

\footnotetext{
${ }^{5} \mathrm{~W}$ Heberden, Commentaries on the history and cure of diseases, Boston, Wells and Lilly, from the final London ed., 1818, pp. 108-11.

6 J Bostock, 'Case of a periodical affection of the eyes and chest', Medico-Chirurgical Transactions, 1819, 10: 161.

7 Ibid, p. 162.

8 Idem, 'On the catarrhus aestivus or summer catarrh', ibid., 1828, 14: 437-46, on p. 440.
}

\footnotetext{
$9 \mathrm{~J} \mathrm{~W}$ Warter (ed.), Selections from the letters of Robert Southey, 4 vols, London, Longman, Brown, Green, Longmans and Roberts, 1856, vol. 4, p. 61.

$10 \mathrm{~J}$ Macculloch, An essay on the remittent and intermittent diseases, London, Longman, 1828, vol. 1, pp. 394-7, on p. 394.

il $\mathrm{W}$ H Cook, The science and practice of medicine, Southport, W H Webb, 1916, pp. 481-5, on p. 482.
} 


\section{Kathryn J Waite}

In 1829 William Gordon (1801-1849) wrote that hay asthma occurs "in particular individuals during the ripening of grass, and evidently caused by the smell given off from its flowers". ${ }^{12}$ He noted that if a patient remained indoors with the windows shut they were less likely to be affected. He suggested various remedies but he was the proponent of the cold shower bath, "which, by its tonic properties, removes that weak and irritable condition which forms the foundation of the disease". ${ }^{13}$ This is one of the first references suggesting an association between hay fever and weakness or nervousness which were to proliferate during the following years.

Hay fever was discussed in the fledgling medical schools. John Elliotson (1786-1868) in one of his lectures at St Thomas's said that he had never heard of it until he read the article by Bostock and also that "A lady told me of it, but I had never heard of it before, and could not tell what she meant by saying that an illustrious person and a noble person had the hay fever". ${ }^{14}$ Elliotson believed that grass flowers caused the problem. He had heard that many of the highest nobility, including several dukes, suffered from the complaint, but he is one of the few authors to note that doctors (or at least physicians) would be less likely to hear about such cases from the lower classes who attended dispensaries; they would be treated for catarrh and since after a while the catarrh would disappear the doctors would not see them again. Elliotson made a plea for any further information about this condition and received several responses to which he alluded in subsequent lectures at the newly founded University of London. ${ }^{15} \mathrm{He}$ received a letter from a medical practitioner from Bristol who, like Elliotson himself, had never previously heard of the disease, indicating that it was not universally well known to medical men. In 1835 Sydney Smith (1771-1845), the great wit, wrote a letter to his son saying "I am suffering from my old complaint, the hay-fever (as it is called) . . If consumption is too powerful for physicians, at least they should not suffer themselves to be outwitted by such a little upstart as hay-fever". ${ }^{16}$ It was almost ten years before anything further was written in the medical literature concerning this "little upstart".

Thomas Watson (1792-1882) included the subject of hay fever in his lectures to medical students at King's College, London, subsequently published in his Lectures on the principles and practice of physic. Therefore by this time a considerable number of practitioners must have come across the condition if only from medical texts and lectures, but there were still relatively few new works on the subject being produced. This is particularly surprising when it is considered that the condition maintained its popularity so that "You may read almost every year in newspapers that one of the English Dukes has gone to Brighton to escape the hay fever". ${ }^{17}$ There were also claims of royal hay fever sufferers. ${ }^{18}$

\footnotetext{
$12 \mathrm{~W}$ Gordon, 'Observations on the nature, cause and treatment of hay asthma', Lond. med. Gaz., $1829,4: 266-9$, p. 266.

13 Ibid., p. 268.

14 J Elliotson, 'Hay fever', Lancet, 1830-1831, ii: 370-3, p. 371, and Lond. med. Gaz., 1831, 8: 411-13, p. 411.

15 Idem, Lond. med. Gaz., 1833, 12: 164-70.

16 L Unger, and H C Harris, 'Stepping stones in allergy. Ch. 2. Hay fever', Ann. Allergy, 1974, 32: 266-78, p. 266.
} 


\section{Nineteenth-Century Treatments}

Many of the references over the next few years concerned treatments which included antispasmodics, expectorants, ipecacuanha, narcotics, the application of caustics to the nose, and avoidance. The various treatment rationales reflected the theories of the cause of the disease; these included heat, light, emanations from grasses, ozone, pollen, benzoic acid and dust. John Hastings (1805-1874), for example, considered that "Hay fever, or hay asthma, as it is sometimes called, is an inflammatory disease, although it has been generally considered a nervous affection, and has consequently been treated with antispasmodics and remedies of that class". ${ }^{19} \mathrm{He}$ also gave the ailment a neural dimension blaming excessive irritation of the superior and inferior laryngeal nerves for contraction of the laryngo-tracheal tube which caused breathing difficulties. ${ }^{20}$ Neural arguments coincided with the rise of neurology as a medical speciality.

G T Gream (1812-1888) suggested the use of nux vomica in the treatment of hay fever. ${ }^{21}$ It had been recommended to him by a friend and "was administered by a friend of his to large numbers of the country people in his neighbourhood, who flocked to him annually for relief, having experienced so much benefit from it". ${ }^{22}$ This is one of the few references to country people suffering from hay fever contrary to what many authors of the time believed. It may be that in this particular district the complaint was recognized as a distinct disease entity, because there was a treatment available that seemed of some use.

\section{Social and Geographical Occurrences}

Philipp Phoebus (1804-1880), Professor of Medicine at the University of Giessen, in 1859 published a plea for information on hay fever, the results of which appeared three years later and did nothing to dispel the myth that it was a disease of the educated. He showed that hay fever had a higher prevalence in England than in any other European country. However authors still disagreed as to just how common it really was; Walter Hayle Walshe (1812-1892) described the illness as an "exceedingly rare occurrence", 23 whilst Pirrie stated that it was in fact a common condition since "almost everyone has met with a sufferer". 24

In the United States, Morrill Wyman (1812-1903) became interested in the disorder. He is famous for being the first physician in the U.S. to perform the surgical drainage of fluid in the pleural cavity by a process that is known as "tapping". ${ }^{25}$ Wyman had been a hay fever sufferer since his student days and spent his summers in the White Mountains, among other places, where he was free of the problem. His own affliction, and that of many others, was different to the one described by European physicians since the European variety tended to occur in May whilst in the United States Rose cold, Hay fever

$19 \mathrm{~J}$ Hastings, Treatise on diseases of the larynx and trachea, London, Longman, Brown, Green, and Longmans, 1850, pp. 23-40, 140-4, on p. 23.

20 Ibid., p. 25.

21 A drug, from the seed of an East Indies tree, which contains strychnine.

22 G T Gream, 'On the use of nux vomica as a remedy in hay-fever', Lancet, 1850, i: 692-3, p. 692 .
${ }^{23} \mathrm{~W} \mathrm{H}$ Walshe, A practical treatise on the diseases of the lungs, 3rd ed., London, Walton and Maberly, 1860, p. 229.

$24 \mathrm{~W}$ Pirrie, On hay asthma and the affection termed hay fever, London, 1867, p. 7.

${ }^{25}$ D Malone (ed.), Dictionary of American biography, 20 vols., London, Humphrey Milford and Oxford University Press, 1936, vol. 20, pp. 584-5. 
or June cold occurred in May or June, but there was also another type that appeared annually in August or September which Wyman named autumnal catarrh. He correlated this with the flowering of the Roman wormwood or ragweed and set out to show that this was indeed the cause of the problem by performing an experiment in the White Mountains where the offending plant was absent. He opened a parcel containing the whole of a Roman wormwood plant causing all the hay fever sufferers present to sneeze, and have itchy, runny noses. He also sent some to other sufferers, who had similar reactions, but the hay fever sufferers who had no contact with the plant remained unaffected. ${ }^{26}$ Wyman became particularly interested in the geographical distribution of the disease and produced various maps showing where it occurred and where the sufferer might be safe during the so called season.

\section{Blackley's Experiments}

However, it was Charles Harrison Blackley (1820-1900) in England who first demonstrated that pollen causes hay fever. Blackley's early education in Bolton was only the most basic and he was apprenticed to Bradshaw, the producer of the famous railway guide, to learn the trade of machine engraving and printing. He attended evening classes in chemistry, botany, electricity, and Greek, continuing these while working as a printer. ${ }^{27}$ He became ill and was a patient of Dr David, a practising homoeopath, who may have stimulated his interest in both medicine and homoeopathy. ${ }^{28}$ In 1855 at the age of 35 , he gave up the printing business and entered the Manchester school of medicine, qualifying in 1858. He continued to live and work in Manchester until his retirement in 1894.

Blackley may have been a general practitioner ${ }^{29}$ or a homoeopath. ${ }^{30}$ In 1874 he went to the University of Brussels where he took the Doctorate of medicine, ${ }^{31}$ a step to make himself more acceptable to the-medical profession at large. He certainly did not hide his interest in homoeopathy. He was an honorary member of the Manchester and Salford Homoeopathic Dispensary, ${ }^{32}$ he published papers in homoeopathic journals, ${ }^{33}$ and in 1862 along with two colleagues he edited the monthly journal The Manchester homoeopathic Observer following an attack on homoeopathy by Dr Roberts. ${ }^{34} \mathrm{He}$ was also an active member of the British Homoeopathic Society.

He was a hay fever sufferer and commenced his experiments on hay fever in 1859. These continued slowly and he did not publish his Experimental researches until $1873 .{ }^{35}$ Blackley performed experiments with the various substances and in the various conditions that were thought to induce hay fever, namely benzoic acid, coumarin, other odours, ozone

\footnotetext{
${ }^{26}$ Morrill Wyman, Autumnal catarrh, New York, Hurd and Houghton, 1872, p. 101.

27 Anon. 'Obituary', Mon. homoepathic Rev., 1900, 44: 634-7, p. 634.

28 Ibid., p. 635.

29 W J Elwood, and A F Tuxford (eds), Some Manchester doctors: a biographical collection to mark the 150th anniversary of the Manchester Medical Society 1834-1984, Manchester University Press, 1984, p. 191.

${ }^{30} \mathrm{~F}$ Bosdin Leech, 'Charles Harrison Blackley of Manchester and hay fever', Br. med. J., 1929, ii: 1171-2, p. 1171.
}

31 G Taylor, and J Walker, 'Charles Harrison Blackley 1820-1900', Clin. Allergy, 1973, 3: 103-8, p. 107.

32 Anon., op. cit., note 27 above, p. 635.

$33 \mathrm{C}$ H Blackley, 'On the influence of infinitesimal quantities in inducing physiological action', Mon. homoeopathic Rev., 1882, 26: 604-18.

34 Anon., op. cit., note 27 above, p. 635.

35 Idem, Experimental researches on the cause and nature of catarrhus aestivus (hay-fever or hayasthma), London, Ballière, Tindall and Cox, 1873, p. 34 . 


\section{The Development of Hay Fever as a Disease of Civilization}

and dust. He did these experiments on himself, at various times of the year, even performing controls. For example, when doing experiments with benzoic acid he applied a solution of benzoic acid to one nostril and a solution containing only alcohol and water to the other.

Using a microscope, he found that the samples of dust which brought on hay fever attacks contained pollen. He used 35 types of pollen in various experiments, applying some to the nostrils, inhaling it, applying it to the conjunctiva, tongue, lips and fauces, and inoculating the upper and lower limbs with the fresh moistened pollen. This last experiment led Blackley to a classic description of the positive skin test for pollen: "In a few minutes after the pollen had been applied the abraded spot began to itch intensely; the parts immediately around the abrasion began to swell ... the swelling seemed to be due to effusion into the subcutaneous cellular tissue". ${ }^{36}$

He carried out atmospheric experiments, constructing his own apparatus for measuring the amount of pollen in the atmosphere which consisted of strips of glass covered with a sticky solution containing glycerine. The number of pollen grains collected could be counted under the microscope. He also attached this to a respirator to measure the amount of pollen inhaled and also constructed kites which exposed the glass slide for a specified length of time allowing him to measure the amount of pollen in the atmosphere at various altitudes. He correlated these results with the severity of his own symptoms.

The second edition of his work, entitled Hay fever: its causes, treatment and effective prevention, included an additional chapter that had previously been published in the Annals of the British Homoeopathic Society. Blackley measured the weight of pollen and calculated that "less than $\frac{1}{40000}$ th of a grain inhaled in each twenty-four hours suffices to bring on the malady in its mildest form" and "rather less than $\frac{1}{3427}$ th of a grain inhaled in each twenty-four hours will keep up hay-fever in its severest form". ${ }^{37}$ These calculations give some credibility to the homoeopathic principle which Blackley developed further in a later paper 'On the influence of infinitesimal quantities in inducing physiological action'. 38

\section{Reactions to Blackley's Work}

Blackley concentrated mainly on the cause of hay fever, showing experimentally, at least on himself, that this was pollen. His conclusion was not universally accepted by the medical world, partly perhaps because of Blackley's unorthodox medical beliefs. Taylor and Walker state that an offer of collaboration with an outside worker was dropped when Blackley's therapeutic interests became known. ${ }^{39}$ But his work did not go unnoticed. Experimental researches was reviewed in several of the leading journals, the London medical Record recommended the work to those who were interested in the subject, ${ }^{40}$ the reviewer in The Doctor ${ }^{41}$ described the book as "instructive and useful", and the Lancet described it as "one of the most interesting that it has been our fortune to read". ${ }^{42}$ The only

36 Ibid., p. 84.

37 Idem, Hayfever: its causes, treatment and effective prevention, London, Ballière, Tindall and Cox, p. 251.

38 Blackley, op. cit., note 33 above.

39 Taylor and Walker, op. cit., note 31 above, p. 107.
40 'George Johnson reviewing Blackley on the causes and nature ...' Lond. med. Rec., 1873, i: 371-3.

41 Anon. 'Review of experimental researches', The Doctor, 1873, 3: 154.

42 Anon., Lancet, 1873, ii: 231-2, p. 231. 


\section{Kathryn J Waite}

criticism that this reviewer made was that to prove conclusively that pollen was generally the cause of hay fever, the experiments needed to be repeated on other people. The book also found itself in the hands of members of the scientific community. Charles Darwin (1809-1882) wrote to Blackley in 1873 exclaiming his astonishment that pollen had such a great power. ${ }^{43} \mathrm{He}$ also sent him a copy of Wyman's Autumnal catarrh which Blackley had not apparently read as it was not listed in the first edition of his book, but was mentioned in the second edition.

Blackley's work did not resolve the debates over the cause of the disease. An editorial in the Lancet in 1874 directed the readers' attention to the work of Hermann von Helmholtz (1821-1894), the inventor of the ophthalmoscope, who had discovered the presence "of uncommon, low organisms in the nasal secretions in this complaint" ${ }^{44} \mathrm{He}$ had also been made aware "of the poisonous action of quinine upon infusoria". 45 He then experimented with quinine, by pipetting a solution into each of the nostrils of a recumbent patient, on whom it worked, as it did on Helmholtz himself, who was also a sufferer.

W Young (1843-1900) was another who rejected the idea that hay fever could be caused by hay, sweet scented vernal grass or ipecacuanha. He stated that "the essential and predisposing cause of this complaint is clearly the result of excess hydrocarbons or heatproducing foods having been partaken of in the warmer season of the year when less of such substances is required, and more than can be soon enough carried off by the liver and lungs". ${ }^{46} \mathrm{He}$ advised patients to live on fresh lean meat and green vegetables, and to take plenty of outdoor exercise.

George M Beard (1839-1883), the famous American proponent of neurasthenia, also rejected Blackley's conclusions, being particularly critical of his ignorance of Wyman's work. ${ }^{47}$ It should be added, that Wyman was a friend of Beard, whom he had met in one of the so-called hay fever resorts. Beard carried out a survey on the disease by sending a very detailed questionnaire to the resorts sufferers visited, and to physicians and to sufferers who were known to him. He also advertised his survey in medical journals and in lay papers and periodicals. From the replies, he constructed a list of more than forty exciting causes and stated that he did not believe that any one specific cause for hay fever would ever be found. However in his conclusions he went on to say that,

In England the principle exciting causes are unquestionably grass and flowers, the pollen and aroma of which are most abundant in early summer, and diminish or disappear later in the season. In the United States the more prominent exciting causes appear to be Roman wormwood and the pollen of corn, both of which flower about the middle of August . . ${ }^{48}$

Beard believed that all forms of the disease were due to the "nervousness" of the patient; people were more likely to suffer their first attack if they had already been

${ }^{43}$ F Burkhardt, and S Smith, et al. (eds), $A$ calendar of the correspondence of Charles Darwin, 1821-1882, London and New York, Garland, 1985, No. 8965. Reprinted in A E Lownes, 'Charles

Darwin to Charles Harrison Blackley', Isis, 1947, 37 : 21-4.

i: 740 .

${ }^{44}$ Anon., 'A remedy for hay fever', Lancet, 1874,

45 Ibid.

46 W Young, 'Hay fever', Lancet, 1874, ii: 145.
${ }^{47}$ For more on George M Beard and neurasthenia see Charles E Rosenberg, 'The place of George M Beard in nineteenth-century psychiatry', Bull. Hist. Med., 1962, 36: 245-59, and Barbara Sicherman,

'The uses of a diagnosis: doctors, patients, and neurasthenia', J. Hist. Med., 1977, 32: 33-54.

48 G M Beard, Hay-fever; or summer catarrh: its nature and treatment, New York, Harper and Bros., 1876, p. 115. 


\section{The Development of Hay Fever as a Disease of Civilization}

exhibiting signs of nervous depression or exhaustion. Hay fever sufferers, in the sample that had responded to the questionnaire, had an increased prevalence of various nervous symptoms which would lead to them having "sick-headaches" and other nervous illnesses. Beard came to the conclusion that "Hay-fever is essentially a neurosis-that is a functional disease of the nervous system. In order to induce an attack, there is necessary first of all a predisposition, frequently hereditary to special and excessive sensibility of the nerves supplying the affected parts". ${ }^{49}$ Beard's ideas on hay fever strongly reflect those on neurasthenia, for example he believed that neurasthenia was largely restricted to the upper classes $^{50}$ and that it was a modern disorder, "for contemporary civilisation alone had produced the peculiar combination of causative agents so deleterious to nerve force: rapid transportation and communication, great advance in scientific learning and the widespread education of women". 51

Elias J Marsh (1835-1908) repeated some of Blackley's experiments following the instructions given in the book and came to the conclusion that "Autumnal catarrh, like the English form of hay fever, is caused by the presence of pollen of flowering plants in the atmosphere, and its irritant action on the respiratory membrane of susceptible persons". 52 Sir Morell Mackenzie (1837-1892) also did experiments like those done by Blackley. In this instance he collected pollen on slips of glass on a train journey from Bognor to Brighton and at other times. He also rubbed pollen onto the nostrils of non-sufferers, which caused a feeling of stuffiness. He concluded that "there can now be little doubt that pollen is the essential factor in the case of those who possess the peculiar predisposition" (author's italics). ${ }^{53}$

During the 1880s a succession of articles and letters appeared in medical journals, mostly concerned with the use of different therapeutic regimes. However the debate over the cause of hay fever continued until the turn of the century when W P Dunbar, a German physician from Hamburg, performed a series of experiments that consisted of inoculating both hay fever sufferers and non-sufferers with pollen toxin, which produced hay fever symptoms only in the hay fever sufferers. "The experiments made a reasonable basis for the conclusion that a group of persons exist who show a specific susceptibility to irritation by the pollen of grasses." 54

\section{Hay Fever's social Status}

The earliest writers had made the observation that the disease tended to occur among the upper classes, for example, Bostock, ${ }^{55}$ and Elliotson, ${ }^{56}$ who wrote that it was "confined to the higher ranks of society", but Elliotson also makes the point that the disease is less likely to be recognized among the lower classes who would put it down as a cold, and even if they did visit a dispensary they would be treated for catarrh, bronchitis or asthma. Gream was one of the few authors to mention that hay fever was present among

49 Ibid., p. 77.

50 J Oppenheim, "Shattered nerves": doctors, patients and depression in Victorian England, Oxford University Press, 1991, p. 104.

51 Ibid., p. 93.

52 E J Marsh, 'Hay fever or pollen poisoning', reprinted in Ann. Allergy., 1962, 20: 45-57, p. 52.

\footnotetext{
53 Mackenzie, op. cit., note 4 above, p. 33.

54 W P Dunbar, 'Etiology and specific therapy of hay fever', Ann. Allergy, 1962, 20: 752-64.

55 Bostock, op. cit., note 8 above, p. 440.

56 Elliotson, op. cit., note 14 above, p. 372.
} 


\section{Kathryn J Waite}

country people in a certain district because there was a treatment available. ${ }^{57}$ However the conviction that hay fever was restricted to the upper classes continued.

Marsh criticized authors for the fact that they had searched for the disease only among the upper classes who made up the greater part of their practices. Marsh carried out a small informal survey among the physicians in the city of Peterson and found that among the fourteen cases of hay fever reported there were two physicians, one bank clerk, one store keeper, one shoemaker and six mechanics. ${ }^{58} \mathrm{He}$ gave this as evidence that the disease "is not at all rare among persons engaged at manual labor". ${ }^{59}$ Other doctors were unable to come up with such evidence. Blackley enquired among the "farming classes" and could not find any symptoms of hay fever. Likewise Beard, when seeking information for his survey, asked physicians in both rural as well as the more deprived areas of cities whether they had seen any patients with hay fever or autumnal catarrh symptoms, to which there was a negative response.

Mackenzie summarized the results of the various authors:

One of the most singular features of this complaint is that it is almost exclusively confined to persons of some education, and generally to those of fair social position. In 1879 I had notes of sixty-one cases of hay fever from my private practice, and had seen many others of which I kept no record, whilst among my hospital patients I have not met with a single instance of the disease. Of forty-eight cases which came . . . under the notice of Blackley, every one belonged to the educated classes; whilst out of fifty-five cases reported by Dr Wyman, in forty-nine the patients were educated people. ${ }^{60}$

Various reasons were put forward to explain the apparent increase of the disease among this class of people. Mackenzie stated that it had either been overlooked in previous ages or that vegetables had increased their "irritating properties" in some way. The theory of change in plants and animals over time had been popularized by Darwin's Origin of species. Marsh had even referred to changes in animals and plants in the Darwinian terms of "struggle for existence" ${ }^{61}$ Blackley pointed out that there was formerly less land under cultivation and that the types of crop being produced had changed but "there can be no doubt that the condition of the nervous system which mental training generates is one which is essentially favourable to the development of the disorder". ${ }^{2}$ According to Blackley, the lower classes were less susceptible to hay fever because they did not have the predisposition caused by academic toil or because they became unsusceptible to pollen because of continued exposure.

Hence education became a prerequisite for being a hay fever sufferer. Hay fever had become "rather a disease of the brain-working than of the muscle-working classes". ${ }^{63}$ Another distinguishing factor was sex. Beard wrote that "of the 433 cases reported by Phoebus, Wyman, and myself, 142, or about one third, were females". 64 He did however qualify this result by saying that men might be exposed more to the exciting causes outof-doors, somewhat contradicting his theory that it was found in those who were educated and had a refined sedentary lifestyle. The distinction between the type of men and women who were most likely to suffer from the disease was further emphasized by McBride:

57 Gream, op. cit., note 22 above, p. 692.

58 Marsh, op. cit., note 52 above, p. 47.

59 Ibid., p. 47.

${ }^{60}$ Mackenzie, op. cit., note 4 above, p. 31 .
${ }^{61}$ Marsh, op. cit., note 52 above, p. 57.

62 Blackley, op. cit., note 35 above, p. 155.

63 Beard, op. cit., note 48 above, p. 45.

64 Ibid., p. 43. 


\section{The Development of Hay Fever as a Disease of Civilization}

the class of persons who suffer most are (1), men (usually young adults) undergoing hard brain work, or of very neurotic temperament; (2), young women of the neurasthenic type. Medical students who are working for an examination furnish, in my experience, quite a large proportion of examples coming under the first category. ${ }^{65}$

Hay fever had therefore developed from being solely a disease which affected the upper classes and the educated, to one which was essentially a neurosis. Beard went so far as to describe the features of a nervous person who was particularly susceptible to this condition. He or she had fine, soft hair, delicate skin, chiselled features, small bones, a small and feeble muscular system, superior intellect, a strong and active emotional nature and was prone to attacks of the nervous system. However this constitution did have its advantages as it produced "immunity from ordinary febrile and inflammatory diseases". 66 Hay fever had become a desirable condition in that it was not only evidence of a sufferer's accomplishment and education, but also of his or her fashionable status.

Hay fever was seen to be hereditary; a rational belief since it took several generations to build up the gentility that was required and once acquired, providing the correct educated lifestyle was followed, would cause subsequent generations to labour under the same disease. Forbes maintained that families who were susceptible to hay fever were also those who were affected by gout for "it is not unreasonable to suppose that gout may be an important factor in the causation of hay fever, by inducing such a condition of the mucous membranes as to render them liable to suffer from the peculiar irritation of pollen". 67

\section{Hay Fever as a Racial Affliction}

Popular ideas concerning race were also reflected in the discussions of hay fever. According to Mackenzie,

the influence of race is seen in the fact that it is the English and Americans who are almost the only sufferers from the complaint. In the north of Europe-that is, in Norway, Sweden and Denmark-it is scarcely ever seen, and it rarely affects the natives of France, Germany, Russia, Italy, or Spain. In Asia and Africa, also, it is only the English who suffer. ${ }^{68}$

No cases were known to Beard among the Negroes or Indians in the United States, the only case being that which Wyman knew of, relating to a coloured child, whose father was an Indian, who had autumnal catarrh and asthma. ${ }^{69}$ Beard explained the appearance of autumnal catarrh only in America as being caused by the greater extremes of climate which resulted in an increased "nervousness".70 Charles Sajous suggested that the Americans and British were the chief sufferers of hay fever because these were the two great tea drinking nations. ${ }^{71}$ The apparent lack of cases among other nationalities and races led Mackenzie to conclude that "national proclivity to hay fever may be taken as a proof of our superiority to other races".72

65 P McBride, 'On hay fever and allied conditions', Br. med. J., 1888, ii: 605-8.

66 Beard, op. cit., note 48 above, p. 82n.

67 L Forbes, Hay fever, hay asthma and excessive sneezing, 2nd ed., London, Renshaw, 1891, p. 17.

68 Mackenzie, op. cit., note 4 above, p. 29.

\footnotetext{
69 Wyman, op. cit., note 26 above, p. 80.

70 Beard op. cit., note 48 above, p. 95.

${ }^{71}$ Charles Sajous, Lectures on the diseases of the nose and throat, Philadelphia, F A Davis, 1890.

72 Mackenzie, op. cit., note 4 above, p. 10.
} 


\section{Kathryn J Waite}

\section{A Disease of Civilization}

Since hay fever was seen as a disease that occurred in some countries more than others, among the educated and upper echelons of society rather than the working classes, occurring in men more than women, being more prevalent in the nervous person and even increasing in prevalence, this led to the development of the concept of hay fever as a "disease of civilization". Cook concluded that "like neuralgia, nervous dyspepsia and other modern neuroses, it is a development of the present over-wrought state of the nervous system of the modern civilised countries". ${ }^{73}$ Dunbar wrote that "the fact of exemption from hay fever of savages and practically of the working classes in civilised countries, as well as other considerations, suggests that we must look upon hay fever as one of the consequences of higher civilisation". ${ }^{74}$

The construct of a "disease of civilization" was by no means new and had been applied in the eighteenth century to gout, giving it desirable connotations. ${ }^{75}$ Class and race tensions increased during the course of the century and the Darwinian view of the struggle for existence developed, all of which gave credence to the concept of "diseases of civilization". George M Beard was a proponent of neurological disease being caused by the stresses and strains of modern society. Society itself could therefore be at the root of ill health.

Since the evidence that nineteenth-century writers collected reflected the cultural and ideological views of the time, hay fever was made to fit the model of a "disease of civilization", and the apparent rise in its prevalence, which Emanuel described as a postindustrial revolution epidemic, gave further weight to this concept. More modern authors too have used the increase in prevalence of hay fever through both the nineteenth and twentieth centuries as evidence that allergies are diseases of civilization. ${ }^{76}$ The concept of hay fever as a "disease of civilization" therefore developed during the nineteenth century and is still being applied to the disease over one hundred years later.

73 Cook, op. cit., note 11 above, p. 483.

74 Dunbar, op. cit., note 54 above, p. 764.

${ }^{75}$ For more on diseases of civilization see Roy Porter, 'Diseases of civilization', in W F Bynum and $\mathrm{R}$ Porter (eds), Companion encyclopedia of the history of medicine, London and New York, Routledge, 1993, vol. 1, pp. 585-600.

76 R Finn, 'John Bostock, hay fever, and the mechanism of allergy', Lancet, 1992, 340: 1453-4. 